DE DE GRUYTER OPEN G

Wioleta Dryl*

Gdańsk University
Journal of Intercultural Management

Vol. 6, No. 4, December 2014, pp.25-37

DOI 10.2478/joim-2014-0033

\title{
The relativity of luxury - a luxury product from a perspective of Polish and foreign consumers
}

\begin{abstract}
Luxury product is a very ambiguous concept. The most commonly cited in the literature barrier to the creation of a universal definition of luxury is the relativity of the concept. The relativity of luxury nature of the product takes the form of regional, temporal, economic, cultural, situational, and also due to the individual characteristics of the consumer.

It should be therefore considered how to shape the product and which marketing tools should be used, to give and keep a luxury image of it. Analysis of the literature in the field of sciences such as management, sociology, psychology or marketing clearly indicates the growing interest in both the concept of luxury as well as luxury goods. It should be noted, however, that according to the results of research on the perception of luxury, consumers from different countries, cultures show different features of the product as important from the point of view of the luxury nature of the good.

The aim of article is identification of differences in the perception of luxury between consumers from different countries, representing different cultures, as well as the specifics of managing a luxury product depending on the country of its origin.
\end{abstract}

Key words: luxury, consumer, relativity

\section{Introduction}

Luxury, by virtue of its subjective nature, is defined in many different ways. This concept lies in the area of interest of many sciences such as sociology, economics, psychology, marketing. Representatives of the various disciplines expose in their definitions, characteristics important from the point of view of sciences which they represent. Thus, in the literature can be found many definitions of both the luxury and luxury product. Despite this strong interest of researchers, the idea of luxury is still a concept arousing numerous discussions. It turns out that the perception

\footnotetext{
*wioleta.dryl@ug.edu.pl
} 
of luxury is being affected by a number of variables associated with the consumer and the way he sees luxury. According to the results of research on the perception of luxury, consumers from different countries, cultures show different features of the product as important from the point of view of the luxury nature of the good.

The main aim of the article is the identification of differences in the perception of luxurious nature of product between consumers from different countries, representing different cultures, as well as the specifics of managing a luxury product depending on the country of its origin.

The article contains an analysis of the literature concerning the essence of luxury products, sources of relativity of luxury, from the perspective of sciences such as economics, psychology, sociology, marketing. Considerations set out in the article are based primarily on foreign literature. It should be emphasized that the subject of luxury, is still described in a very narrow range in Polish literature.

An important point of the article is the analysis of the research conducted among consumers in other countries in the area of perception of luxury nature of the products. The author of article also attempts to identify the differences and similarities that exist in this area between Polish and foreign consumers. It should be noted, however, that in-depth understanding of the problem, requires initiation of own international research that is currently being prepared by the author of the article.

\section{The problem of relativity of luxury and its impact on the knowledge of the essence of a luxury product}

The most commonly cited in the literature barrier to the creation of a universal definition of luxury is the relativity of this concept. Definitions of luxury and luxury product presented in the literature are often ambiguous and therefore create a field for reasoned discussion. Unquestioned authority in the field of brand management J. N. Kapferer has treated the problem of luxury comprehensively, creating two definitions of luxury product. Based on an extensive literature study, J. N. Kapferer stated: „There is no single definition of luxury. Most of them do refer to well crafted, hedonistic and aesthetic objects, priced excessively above their functional utility, sold in exclusive stores delivering personal service and unique consumer experience, most often from a brand with history, heritage, the whole delivering a rare feeling of exclusivity" [Kapferer J., 2011, pp. 251-260]. This definition sets out the problem of luxury very comprehensively, but still, as the author observes leaves a degree of ambiguity. Luxury nowadays becomes more and more available, and the boundary between the mass and luxury is becoming less clear. Increasingly, luxury is not considered in the category of products, but brands. So dilemmas associated with luxury products are based on the question ,what to have", not as it once was „to have or not to have". Therefore, J. Kapferer distinguishes two types of luxury, namely "absolute and relative luxury”. „Relative luxury” refers to the definition 
provided above, which is based on subjective assessment of feelings, consumers' experiences, associated with acquired brand. Explaining the concept of ,absolute luxury" author refers to the reality of the beginning of the last century: „At the begenning of the 20th century living in a mansion, with the latest comfort, driving a car, going skiing were in themselves sign of luxury [...]. No brand was needed at that time: this absolute luxury was by essence conspicous, visible by all, walking in the streets of New York, or London or Paris or along the wharfs" [Scholz L., 2013, pp. 12-14].

This approach, however, still does not clarify the boundary between luxury and mass product. Therefore, it is necessary to indicate the wide and at the same time the specific context in which luxury is defined. According to L. Scholz proper definition of luxury requires the recognition of the socio-economic context. J. Kapferers' definition of "relative luxury” applies in affluent western society. On the other hand, the "absolute luxury" is located at a specific time, and only at this point the definition of luxury is correct. The conclusion from the above analysis is that, the relativity of luxury is not only due to the socio-economic context, but also refers for example to time.

K. Heine and T. Sikora recognize the multidimensional nature of the relativity of luxury. According to the authors, the relativity of the luxurious nature of the product has the regional, time, economic, cultural and situational form.

The source of regional relativity is the diversity of the local availability of specific products. Due to the rarity of the specific product in the region, it assumes the title of luxury. While in other parts of the world it is a widespread good, available to consumers with average incomes [Heine K., Sikora T., 2012, pp. 3].

Interesting results, clearly showing the specificity of regional relativity of luxury, were obtained from research conducted by Euromonitor Internetional Analyst Pulse in May 2013. The study focused on the perception of luxurious character of cosmetic products brands, in regional breakdown. According to the study, for example, Chanel was seen as a luxury by all respondents from the Asia-Pacific region, while in the United States and Canada, $12 \%$ of respondents considered it as a mass.

General conclusions of the above-cited studies point to the fact that in developed markets, some brands are considered mass, while in the emerging markets the same brands are perceived as luxurious.

Time relativity refers to the perception of a luxury nature of the product, depending on the passage of time. Relativity is mainly due to the availability of product, and the degree of its desire at a certain time [Matsuyama K., 2002, pp. 1038], what is the consequence of dynamic changes in technology and social trends [Schiereck D., Königs A., 2006, pp. 2].

The perception of luxury nature of the product changes over time, the same as consumers' needs and desires change. Products which today are seen as luxury, for 
some time can be common, mass products. On this basis, C. Berry defines luxury as a short-term, transient phenomenon. Maintaining the luxury image of the product, requires from the manufacturer the use of certain, very specific set of tools and resources, as well as constant monitoring of the needs and expectations of their customers [Berry C., 1994, pp. 41].

Whether the product will be perceived as a luxury or widespread, according to K. Heine and T. Sikora, may also depend on the situation. The more often the consumer is able to consume, or use certain products, the less luxurious to him they seem. Situational relativity can thus, for example, relate to the frequency of use of the product.

The most frequently mentioned factor influencing the perception of the luxurious nature of the product is the consumers' income. Economic relativity of luxury, inter alia refers to the disparities between the wealth of buyers, which ultimately translates to their purchasing power. Economic relativity may also be based on the differences in the economic development of particular regions of the world [Heine K., Sikora T., 2012, pp. 3]. Until recently, the Polish consumers were not a group of target audience for luxury goods. This resulted from both not enough high income of Poles and the low level of economic development of the country. For over twenty years, this market is growing extremely rapidly, however, [KPMG Report, 2010, pp. 15].

In contrast to the above-mentioned sources of relativity, cultural relativity does not have its grounding in the availability of products, but the extent of their desire. According to K. Heine and T. Sikora products, which in some cultures are luxurious in others may be common, or even undesirable. This situation may refer not only to the specific cultures taken as a whole but also of certain subcultures. According to D. Mortelmans [Mortelmans D., 2005, p. 497] "every social group has its own luxury". Particular cultures or subcultures have certain canons of good taste, liking, and hence views about the luxurious nature of the product.

It should be noted that apart from indicated by K. Heine and T. Sikora, sources of relativity of luxury, there are also factors such as basic demographic variables, namely age, sex, education, which also shape the perception of the luxurious nature of the product. The authors mention them by taking a reflection on the cultural relativity of luxury. It should be noted, however, that within certain cultures, the different age groups or representatives of specific gender may have a different attitude to the luxurious character of the same products.

Relativity of luxury can also be the result of specific psychological determinants, lifestyle of buyers. Certain products may be at the same time, place, situation, culture, and at a similar level of consumer income perceived as luxury or unnecessary, undesirable or common. On the one hand, it could be argued on the basis of considerations of K. Heine and T. Sikora, that the differences in the perception of 
the luxurious nature of the product, comes from the cultural relativity, as it is the consequence of various degrees of desire of product. On the other, the source of relativity is a different lifestyle of these consumers.

Interesting approach to the determinants of the perception of luxurious nature of the product presents F. H. Seringhaus. According to the author perception of luxury is influenced by demographics, habit, lifestyle, social environment, and the marketers - in the opinion of F. H. Seringaus: the purveyors of luxuries [Seringhaus F. H., 2002, pp. 4]. Although the author presents an incomplete picture of the problem, at the same time identifies the factor, not yet indicated as important for the perception of luxury which means the marketers.

In conclusion of the above considerations, it can be seen that the correct definition of luxury, and consequently luxury product requires clarification of the context in which the terms are considered. The perception of luxury is conditioned by many factors. It turns out that various social groups, different cultures, and even generations living in different periods of time have "their luxury".

For the purposes of this article, a luxury product will be considered from the point of view of dimensions of luxury value perception. It is an interdisciplinary approach to the concept of luxury product. The perception of product value is based on both situational variables and individual characteristics of the consumer. The key dimensions of the perception of luxury product include financial, functional, personal and social value. These dimensions are strongly correlated with each other. Their comprehensive range is shown in Figure 1.

Figure 1. Dimensions of luxury value perceptions

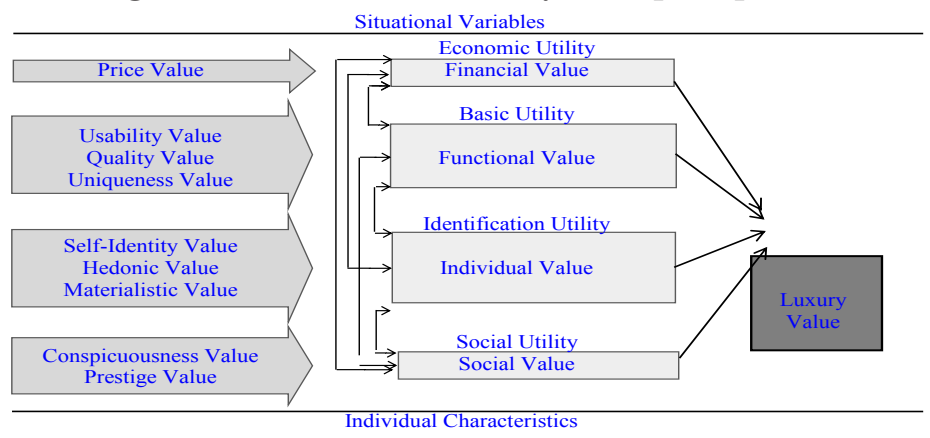

Source: [own work on basis: Hennigs N., Wiedmann K. P., Klarmann Ch. (2012), pp. 32].

In conclusion of the above considerations, it can be seen that the correct definition of luxury, and consequently luxury product, requires clarification of the context in which the terms are considered. The perception of luxury is conditioned by many factors. It turns out that various social groups, different cultures, and even generations living in different periods of time have "their luxury". 


\section{The perception of luxurious nature of the product from the perspective of manufacturers of luxury goods.}

One of the essential elements of luxury brand is its origin. Many companies in the sector of luxury, position their brands in a strong relationship with the country of their birth [Chevalier M., Mazzalovo G., 2008, pp. 185, Money R. B., Colton D., 2000, pp. 189 - 205, Oetzel J., Doh J. P., 2009, pp. 108 - 120]. The origin of the brand has also a strong influence on the strategies of shaping brand image in the consumers' minds. Manufacturers of luxury goods often stress their roots. On the one hand, they want to keep a unified image, consistent with the rules created at the inception of the brand. On the other hand, they want to reach a specific group of buyers who prefer brands with specific roots.

It must therefore be noted that the relativity of luxury has its roots not only in the specific characteristics of the consumer, but also the different strategies of manufacturers from different countries. So it seems important to gain knowledge about determinants of luxurious nature of the product, including those created by the manufacturers.

A rich source of knowledge in this field, may be experience of companies belonging to the elite organizations associating producers of luxury goods, as well as the requirements and rules imposed to new members of these organizations. The oldest and also the most rapidly changing organization of this type is founded in 1954 in France Comite Colbert associating major French luxury brands, and dedicated to the promotion of these brands in global markets [http://www.comitecolbert.com/histoire.html, (05 October 2014)].

The main objective of the association, has always been uniting the French luxury goods manufacturers, encouraging to the export of these goods, promoting the sharing of knowledge on luxury craft. Comite Colbert setting the canons of luxury, requires of its members fulfilling four basic conditions, their products must be characterized by: international ambition and strong cultural identity, high quality standards, creativity, imagination and ethical conduct [http://www.comitecolbert. com/les_maisons.html, (06 October 20140]. Comite Colbert puts the particular emphasis on strong relationships of its members with culture. In addition, as the only organization of this kind requires ethical conduct. A very interesting fact is that, until recently, Comite Colbert has placed completely different demands on its members, such as: high price, strong brand associated with exclusive life style, very high quality and design at the highest level. As can be seen, the organization remains consistent, in the matter of the high quality of products. One should notice, that existing requirements of the organization, reflect to essential marketing principles of luxury goods. New requirements attest the fact that Comite Colbert is heading with the spirit of the times. The strong emphasis is being put on the creativity, imagination. 
An Altagamma Foundation, consisting of Italian producers of luxury goods is an organization considerably younger than Comite Colbert (formed in 1992), although acting in very active and creative way. According to the statute of association, Altagamma is aspiring to establish the primacy of an Italian lifestyle and the culture worldwide, through support and the promotion of the best artistic, cultural and industrial quality of country. Stressing in particular the quality, innovation, design, prestige and high standards of service as distinguishing features of Italian products, culture and art [http://www.altagamma.it/sezione2.php?Id=2\&Lingua=ing (10 October 2014)].

Apart from Altagamma and Comite Colbert on the Euromarket there are also functioning British, Spanish and German associations. British Walpole came into existence in 1990. The main objective of the organization is promotion of British luxury brands in the world. Thanks to the membership in Walpole enterprises have also a chance for the exchange of experiences, of knowledge in managing the luxury brand. Walpole demands high standards of its members in the scope of quality, style, design, craftsmanship, creativity, services and innovations.

German Meisterkreis established in 2011 is the youngest organization consisting of producers of luxury goods. Meisterkreis sets before its members the most stringent conditions, including the financial results and the duration of existence on the market. In accordance with the requirements of organization luxury brand must:

- represent the highest standards in terms of quality, design, service, creativity and innovation, craftsmenship

- enjoy an outstanding reputation

- has been present in Germany for at least 3 years

- achieve minimum turnover rate in Germany is 5 million euros.

- be positioned at the top price segments of its category

- be managed in Germany by an independent organization

- comply with the basic principles of selective distribution

- share and actively supports the philosophy, mission and goals of the Meisterkreis. [http://www.meisterkreis-germany.com/en/members/admissions-criteria (10 October 2014)]

It should be noted that from the point of view of the representatives of the finest luxury brands associated in the above-mentioned organizations, the most important features of luxury brands are the highest standards of quality, craftsmanship and design. All organizations require from members also innovation.

Demands which organizations of producers of luxury goods place on their members can be a determinant in shaping the identity of the brand of luxury companies operating in this highly specific market. Luxury product, however, must first and foremost meet the very sophisticated and specific needs of its consumers. Although the requirements of associations of finest luxury brands are similar, it appears that the requirements of their buyers often differ significantly. Therefore, 
the luxury goods manufacturers, wanting to adjust to the changing expectations of consumers, diversify their offer, use different marketing tools for the individual segments.

\section{How do luxury value perceptions differ across countries?}

The results of numerous international studies confirm the fact that the perception of the luxurious nature of the product varies from country to country. Researchers in recent years have recognized that theoretical models of consumers behavior of luxury goods in a particular country, can not perform in other countries [Hofstede G., Hofstede G. J. (2004), pp. 25 - 28, Hult G. T. M., Keillor B. D. , Hightower R. (2000), pp. 206 - 220, Tynan C., McKechine S., Chhuon C. (2010), pp. $1156-1263]$.

Researches in this area, most often are based on division of: developed markets including United States, Japan, Unted Kingdom and emerging markets such as China, Brazil, India, Russia [Dubois B., Czellar S., Laurent G. (2005), pp. 115 - 128, Shukla P. (2010), pp. 108 - 129, Wiedmann K. P., Hennings N., Siebels A. (2009), pp. 625 - 651, Wiedmann K. P., Hennings N., Siebels A. (2009), pp. 625 - 651], or Asian and Western societies [Wang P. Z., Waller D. S., (2006), pp. 665 - 687, Wong N. Y., Ahuvia A. C. (1998), pp. 423 - 441].

Previous studies have shown significant differences in the perception of the luxurious nature of goods between the Eastern and Western cultures [Podoshen J. S., Li L., Zhang J. (2011), pp. 17 - 25 2011, Shukla P. (2010), pp. 108 - 129, Tsai S. P. (2005), pp. 177 -206]. It was noted also, that the relativity of luxurious nature of the product may result in a lesser degree from cultural differences in individual market segments than from cross-national context. It absolutely does not change the fact that culture has an impact on the relativity of perception of luxury. According to the researches of Laurent and Dubois (1994) conducted in France and Tidwell and Dubois (1996) in Australia, the culture does influence the perception of luxury [Tidwell P., Dubois B. (1996), pp. 31 - 35].

In the literature, can be found many researches based on a comparison of the perception of luxurious character of the product in two selected countries. One of such studies was conducted in India (a developing, Eastern, collectivist and rapidly growing luxury market) and the UK (developed, Western, individualist and mature luxury market). Author of the study analyzed the four-element model of luxury value perception including financial, individual, social and functional value dimension. The results show not only significant differences but also many similarities in the perception of luxury nature of the product in those countries. Consumers in the UK as well as from India, purchase luxury goods to manifest their superior image in the eyes of others (social value dimension). At the same time it was noted that Indian consumers look for fitting - in behavior, more than the Brits, and their consumption depends on social acceptance [Shukla P. (2011), pp. 242-52]. 
It was also noted, that for British consumers, information and opinions of other consumers about luxury goods are less important than for the Indian consumers. British consumers are seen as strong individualists. Therefore, the opinion of others about luxury product is for them less important than, for example, the brand origin (individual value dimension). According to cited research, consumers in developed countries rely more on brand origin cues than in developing markets. At the same time, there was also detected in research, a very strong effect of brand image on consumers' purchasing decisions of both countries. Consumers want to have a brand which image is synonymous with the image of social group they wish to associate with.

Studies on a larger scale were carried out by the researchers: N. Hennings, K. P. Wiedmann, Ch. Klarmann, S. Strehlau, B. Godey, D. Pederzoli, A. Neulinger, K. Dave, G. Aiello, R. Donvito, K. Taro, J. Taborecka - Petrovicova, C. Rodriguea Santos, J. Jung, H. Oh. The authors conducted a survey on consumers in Brazil, France, Germany, Hungary, India, Italy, Japan, Slovakia, Spain, United States and other countries, total 1275 respondents. Like in case of the previously described study, authors have tested the perception of luxury product in terms of its financial, functional, individual and social value dimension [N. Hennings, K. P. Wiedmann, Ch. Klarmann, et.al, (2012), pp. 1018 - 1034].

In case of consumers from Germany and United States, financial aspects do not affect the perception of the luxurious nature of the product. In case of the factors that make up the financial dimension value, there were noted significant differences between the American and French consumers. According to French consumers, luxury should be available only for selected groups of consumers, and only at certain points of sale. While Americans believe that luxury products are not in contradiction with mass production.

In the case of functional value dimension, there were also revealed significant differences among the surveyed countries. German consumers attach great importance to quality and performance aspects. According to Germans' perception of luxury, luxury brand should primarily represent the highest quality. Whether it is desired by other consumers, is no longer crucial. Those consumers put quality over prestige when considering the purchase of a luxury brand.

With respect to the individual dimension focusing on self-pleasure and materialistic aspects of luxury consumption, for American consumers followed by India, Brazil and Italy the most important are hedonic, affective and materialistic aspects of luxury consumption. Spanish consumers in the slightest are guided by hedonism while making purchase decisions. At the same time, in the case of social dimension emphasizing prestige and opinions of others, Spanish and Italian consumers are not concerned about what other think of them. In the same area, Indian consumers attach great importance to the opinion of other consumers about luxury brands character. The individual dimension is also important for them. 
The cited studies clearly showed the significant cross-cultural differences between the luxury value dimensions as perceived by consumers from different countries. The perception of luxury is dependent on many factors, which at the same time, have a different level of significance in different countries.

At this point, it should be considered, how the Polish consumers perceive luxury and what are their requirements for a luxury product. According to the KPMG study from 2013, the vast majority of Polish consumers (89\%) consider the luxurious character of product from the perspective of its high quality. So it turns out, that Polish consumers, like German, consider the functional value dimension as the most important characteristic of a luxury product. For over half of the consumers, luxury product is associated with prestige (61\%). Social value dimension of luxury product for Polish consumers, is just as important as for the Indian consumers.

The financial value dimension of luxury value perception, focusing on price of luxury products is regarded important by half of polish consumers. Comparing the results of polish research in this area with research of foreign consumers it can be seen that once again the Polish consumer has a similar attitude towards luxury to the attitudes of the representatives of developed countries such as France, Hungary, Italy, Brazil and Slovakia.

A very interesting conclusion from the research undertaken by N. Henning et al, is segmentation of the consumers of luxury goods based on luxury value perception. The authors divided the consumers of luxury goods into the following four categories:

- The Luxury Lovers - consumers who believe that luxury goods are exclusive, guarantee their uniqueness and cannot be mass-produced (primarily consists of the U.S., Indian, Hungarian, and Brazilian consumers);

- The Status-Seeking Hedonists - consumers who focus on self-satisfaction and pleasure and less on the price and quality values of luxury goods (the U.S., Indian, Japanese, and Brazilian consumers);

- The Satisfied Unpretentious - consumers who emphasize quality assurance over prestige and is less focused on impressing others (Spanish, Hungarian, Slovakian consumers); and

- The Rational Functionalists - consumers who value performance of a luxury brand more than the opinions of others (the U.S. and German consumers) [N. Hennings, K. P. Wiedmann, Ch. Klarmann, et.al, (2012), pp. 1028 - 1030].

Unambiguous indication of the Polish consumer in so constructed segmentation is not possible. But it is possible to find common characteristics of Polish consumers and consumers belonging to the so-designated segments. Closest to the Polish consumer way of perception of luxury represent The Satisfied Unpretentious. For consumers in this segment the most important factor in the perception of luxury is quality. In the biggest contradiction with the approach of the Polish consumer to 
factors relevant to the perception of luxury product, are standing representatives of the segment "Status - Seeking Hedonists".

\section{Final remarks}

The correct definition of luxury, and consequently luxury product requires clarification of the context in which the terms are considered. The perception of luxury is conditioned by many factors. It turns out that various social groups, different cultures, and even generations living in different periods of time have "their own luxury". Researchers on the base of numerous studies have recognized that theoretical models of luxury goods consumers behavior in a particular country, can not perform in other countries.

There have been found significant differences in the perception of the luxurious nature of goods between the Eastern and Western cultures, developed markets including United States, Japan, United Kingdom and emerging markets such as China, Brazil, India, Russia. There are also conducted studies based on comparison of approach of two selected countries to the concept of luxury and its main characteristics.

So far, none of this type of comparative studies included Polish consumers. It seems reasonable to identify factors important in the case of Polish consumers perception of the luxury nature of goods. Identification of these factors provides a basis for further comparative international research in this area. The author recognizes the important research gaps, precisely in terms of similarities and differences in the Polish and foreign consumers perception of luxury. The previous theoretical considerations undertaken by the author of the article in terms of luxury products are to be the basis for planned by the author, international comparative research of perception of luxury nature of the products.

However, taking into account the results of research on Polish consumers perception of luxury, there can be found some similarities and differences between the approach of Polish and foreign consumers. Comparing the results of polish research in this area with research of foreign consumers it can be seen that the Polish consumer has a similar attitude towards luxury to the attitudes of the representatives of developed countries such as France, Hungary, Italy, Brazil and Slovakia. For these consumers the most important factor in the perception of luxury is quality. In the biggest contradiction with the approach of the Polish consumer to factors relevant to the perception of luxury product, are standing U.S., Indian, Japanese, and Brazilian consumers.

It should be noted that such a large discrepancy in the way of perception of the luxury for consumers from different countries, is the enormous challenge for the manufacturers of luxury goods. Meeting such diverse consumer demands is forcing manufacturers to adapt their marketing strategies to the corresponding segments of the market. 


\section{References}

Berry, C. (1994), The idea of luxury: A conceptual and historical investigation, New York: Cambridge University Press.

Chevalier, M., Mazzalovo, G. (2008), Luxury Brand Management: A World of Privilege, John Wiley\&Sons, NJ, pp. 185.

Dubois, B. Czellar, S. Laurent, G. (2005), 'Consumer segments based on attitudes toward luxury: empirical evidence from twenty countries', Marketing Letters, vol. 16, no. 2, pp. $115-128$.

Heine, K., Sikora, T. (2012) Pojecie marki luksusowej, [Online], Available: http://conceptofluxurybrands.com/content/20121107_Heine_The-Concept-of-Luxury-Brands.pdf [10 October 2014].

Hennigs, N., Wiedmann, K. P., Klarmann, Ch. (2012), 'Luxury Brands in the Digital Age - Exclusivity versus Ubiquity’, Marketing Review, vol. 29, no. 1, pp. 32.

Hennings, N., Wiedmann, K. P., Klarmann, Ch., Strehlau, S., Godey, B., Pederzoli, D., Neulinger, A., Dave, K., Aiello, G., Donvito, R., Taro, K., Taborecka - Petrovicova, J., Rodriguea Santos C., Jung, J., Oh, H. (2012), 'What is the Value of Luxury? A CrossCultural Consumer Perspective', Psychology and Marketing, vol. 29, no. 12, pp. 1018- 1034.

Hofstede, G., Hofstede, G. J. (2004) Cultures and Organizations: Software of the Mind, London: McGraw-Hill.

Hult, G. T. M., Keillor, B. D., Hightower, R. (2000) 'Valued product attributes in an emerging market: a comparison between French and Malaysian consumers', Journal of World Business, no. 35, pp. $206-220$.

Kapferer, J. (1997) 'Managing luxury brands', Journal of Brand Management, vol. 4, no. 4, pp. 251-260.

Königs, A., Schiereck, D. (2006), 'Wealth Creation by M\&A Activities in the Luxury Goods Industry', Working Paper, no. 7, pp. 2.

KPMG Report, 2010, pp. 15.

Matsuyama, K. (2002), 'The Rise of Consumption Societies', Journal of Political Economy, vol. 110, no. 5, pp. 1038.

Money, R. B., Colton, D. (2000), 'The response of the „new consumer” to promotion in the transition economies of the former Soviet Bloc', Journal of World Business, vol. 35, pp $189-205$.

Mortelmans, D. (2005), 'Sign Values in Processes of Distinction: The Concept of Luxury', Semiotica, vol. 157, no. 1/4, pp. 497 - 520.

Oetzel, J., Doh, J. P. (2009), 'MNEs and developement: a review and reconceptualization', Journal of World Business, no. 44, pp. 108 - 120.

Podoshen, J. S., Li, L., Zang, J. (2011), 'Materialism and conspicuous consumption in China: a cross - cultural examination', International Journal of Consumer Studies, vol. 35, no. 1, pp. $17-25$. 
Scholz, L. (2013), Brand Management of Luxury Goods. From the historical development of luxury to our present-day perception, Hamburg: Anchor Academic Publishing.

Seringhaus, F. H. (2002), 'Cross-cultural exploration of Global Brands and the Internet', 18th Annual IMP Conference - Conference Proceedeings, Dijon, pp. 4.

Shukla, P. (2010), 'Status Consumption in Cross - national Context: Socio - psychological, Brand and Situational Antecedents', International Marketing Review, vol. 27, no. 1, p. 108 129.

Shukla, P. (2011), 'Impact of interpersonal influences, brand origin and brand image on luxury purchase intentions: measuring interfunctional interactions and a cross-national comparison', Journal of World Business, vol. 46, no. 2, pp. 242-52.

Tynan, C., McKechnie, S., Chhuon, C. (2010), 'Co-creating Value for Luxury Brands', Journal of Business Research, Vol.63. no. 11, pp. 1156-1263.

Tsai, S. P. (2005), 'Impact of personal orientation on luxury - brand purchase value', International Journal of Market Research, vol. 47, no.4, pp. 177 - 206.

Tidwell, P., Dubois, B. (1996), ,A cross-cultural comparison of attitudes toward the luxury concept in Australia and France', Asia Pacific Advances in Consumer Research, vol. 2, pp. 3135.

Wang, P. Z., Waller, D. S. (2006), 'Measuring consumer vanity: A cross-cultural validation', Psychology and Marketing, vol. 23, no. 8, pp. 665-687.

Wiedmann, K. P., Hennings, N., Siebels, A. (2009), 'Value - based segmentation of luxury consumption behavior', Psychology and Marketing, vol. 26, no. 7, p. 625-651.

Wong, N. Y., Ahuvia, A. C. (1998), ,Personal Taste and Family Face: Luxury Consumption in Confucian and Western Societies', Psychology and Marketing, vol. 15, no. 5, pp. 423- 441.

http://www.comitecolbert.com/histoire.html [05 October 2014]. 